\title{
INTERSUBJETIVIDAD, INTERCULTURALIDAD Y POLÍTICA DESDE LA FILOSOFÍA PARA LA PAZ
}

\section{INTERSUBJECTIVITY, INTERCULTURALITY AND POLITICS FROM THE PHILOSOPHY FOR PEACE}

\author{
Vicent Martínez Guzmán ${ }^{1}$ \\ Universitat Jaume I (España)
}

Recibido: 30-11-2014

Aceptado: 02-02-2015

Resumen: Propongo que la base de la política es la intersubjetividad. 1) Interpreto la experiencia originaria del filosofar, thaumazein, como el descubrimiento de la alteridad que puede producir violencia, pero también el reconocimiento de que los seres humanos estamos interrelacionados intersubjetivamente y podemos organizarnos políticamente. 2) Trato de desligar el poder político de la violencia: siguiendo a Arendt el poder es la frágil capacidad de concertación que surge de vivir juntos. Reflexionamos también sobre los conflictos en la política, la cleptocracia y la necesidad de moralizar la política y de la austeridad. 3) La injusticia discursiva se produce cuando a una persona desempoderada no se le reconocen la emisión de actos de habla con la fuerza ilocucionaria que pretende. Palabras-clave: Intersubjetividad, interculturalidad, política, poder, performatividad.

\begin{abstract}
I suggest that the ground for politics is intersubjectivity. 1) The original experience of philosophy, thaumazein, is the discovery of otherness. It can resort to violence but it can too recognize that human beings are related intersubjectively and can organize politically. 2) I try to separate political power from violence: according to Arendt power is the frail capacity to act in concert that comes out of our living together. We also take into account conflicts in politics, cleptocracy, the relationship between morality and politics and austerity. 3) There is discursive injustice when someone utters a speech act that does not have the illocutionary effect of uptake because she is a disempowered person.

Key-words: Intersubjectivity, interculturality, politics, power, performativity.
\end{abstract}

[1] (martguz@uji.es) Director honorífico de la Cátedra UNESCO de Filosofia para la Paz de la Universitat Jaume I de Castellón. Fundador del Máster y Doctorado en Estudios Internacionales de Paz, Conflictos y Desarrollo. Entre sus publicaciones Filosofía para hacer las paces y Podemos hacer las paces. 


\section{Admiración, miedo y política}

A partir de la experiencia del thaumazein, la toma de conciencia de la alteridad puede producir miedo y provocar una reacción de dominio del otro o la otra. Sin embargo, también puede ser el descubrimiento de la intersubjetividad por la cual la configuración de la propia identidad personal o colectiva y, por tanto cultural, siempre se hace en interrelación con otras personas y colectivos. Por consiguiente nos produce admiración o asombro descubrir cuán interrelacionados estamos los seres humanos y organizamos nuestra convivencia política según esta intersubjetividad. En nuestra propuesta, la ruptura de la intersubjetividad es el inicio de la violencia. Veámoslo:

1) De acuerdo con Platón ${ }^{2}$ y Aristóteles ${ }^{3}$ la filosofía surge del thaumazein: asombrarse, admirarse, quedar estupefacto, atónito; en mi interpretación, ante la alteridad de la naturaleza y de los otros y las otras. Platón recuerda el mito de Taumas o Taumante (thauma: maravilla, prodigio, y de ahí taumaturgo: el que hace milagros) padre de Iris (la de la maravilla de los colores del arco iris) que personifica la filosofía porque es la mensajera de los dioses (función que también tiene Hermes) y relaciona su etimología con el verbo eírein sinónimo de légein que significa hablar. Por consiguiente, según el mito y los mensajes de los dioses (principalmente de Hera), la filosofía (Iris) sería hablar desde la admiración.

2) Aristóteles resalta que nos admiramos desde la ignorancia y por eso comenzamos a filosofar, a amar la sabiduría, por razón del conocimiento mismo y no por ninguna utilidad.

3) Una interpretación relaciona la actitud de quedarse atónito frente a las aporías lógicas o lingüísticas, pero tiene interpretaciones más complejas.

4) También he encontrado un sentido de admiración como "reverencia» (Erfurcht) por ejemplo ante la ley moral que, algún autor, ${ }^{4}$ retrotrae a Kant en la Critica del Juicio §2.

5) Husserl, interpretado desde el idealismo egológico, se refiere en Ideas III al yo puro y a la conciencia pura como la maravilla de las maravillas (das Wunder aller Wunder ist reines Ich und reines Bewußtsein). En la «Conferencia de Viena" y en la Crisis habla del thaumazein como el origen de la actitud teorética por la que nos liberamos de los caprichos de la vida diaria. ${ }^{5}$ Nos ocupamos de la relación entre intersubjetividad y nuestra propuesta de hacer las paces, según Husserl, en otro contexto. ${ }^{6}$

[2] Teeteto 154b6-155c7.

[3] Metafísica $982 \mathrm{~b}-983^{\mathrm{a}}$.

[4] Roesch-Marsh, E.: «Sobering up with Levinas: Trauma, Étonnement, and the Anarchy of Philosophy» en The Heythrop Journal 44, 3, 2003.

[5] Kingwell, M.: «Husserl's Sense of Wonder» en The Philosophical Forum 31, 1, 2000.

[6] París Albert, S., Comins Mingol, I. y Martínez Guzmán, V.: «Algunos elementos fenomenológicos para una filosofía para hacer las paces» en Investigaciones Fenomenológicas vol. monog, 2011, p 331-348.

THÉMATA. Revista de Filosofía, N52 julio-diciembre (2015) pp.: 147-158

doi: 10.12795/themata.2015.i52.08 
6) Heidegger considera la admiración (Erstaunen; aunque Heidegger distingue entre Berwunderung, Verwunderung, Bestaunen, y Er-staunen que no voy a desarrollar) como un estado de ánimo fundamental (Grundstimmung, originary mood).$^{7}$ En el origen de la filosofía griega ${ }^{8}$ Erstaunen sería el asombro ontológico, el filósofo que se queda anonadado ante el Ser de los seres. Es interesante destacar que, en nuestra interpretación, el asombro o admiración como el origen del filosofar como estado de ánimo, es más que un concepto. Siguiendo a Heidegger no es mero logos, simple razón, por más que expliquemos el paso del mito al logos, sino que es también un pathos, un sentimiento. Así desde la misma experiencia original del filosofar tenemos superada la dicotomía entre razón y sentimiento. ${ }^{9}$

7) Según el trabajo que estamos siguiendo de Roesch-Marsh, Levinas, aún reconociendo la importancia de la intersubjetividad en Husserl, sigue manteniendo una interpretación desde el idealismo egológico y presenta una alternativa: es la relación con la otra persona la que nos deja atónitos (astonishing, étonnement). Ya no es una vuelta del ego sobre sí mismo, confirmando su autonomía, sino que atestigua una trascendencia anterior a toda posición del sujeto y antecede a todo contenido mental percibido o asimilado. El asombro que produce la intersubjetividad descabalga al yo y lo deja a la deriva. El ego debe ser desarraigado de su arraigo en si mismo, «despertado» por el otro. La metáfora que utiliza es que el yo tiene el peligro de estar embriagado o ebrio de si mismo y la relación intersubjetiva lo desembriaga, lo hace sobrio (sobering $u p$, es el verbo usado por el autor del artículo en que comenta a Levinas), lo descentra o desnucleariza (dénucléation) de su propio yo.

En la interpretación en que venimos trabajando, esta experiencia de admiración o asombro nos hace descubrir la alteridad de la naturaleza y la presencia intersubjetiva de otros seres humanos. Este descubrimiento puede producir miedo. ${ }^{10} \mathrm{El}$ descubrimiento de nuestra pertenencia a la tierra, de nuestra «terrestrialidad» puede ser un síntoma de nuestra fragilidad y nos produce miedo. La presencia de los otros, especialmente según la investigación feminista de la paz, de «las otras» y nuestra relación de dependencia con ellas, ${ }^{11}$ también es un síntoma de nuestra fragilidad y puede producir, así mismo, miedo.

[7] Stone, B.: «Curiosity as the thief of wonder: an essay on Heidegger's critique of the ordinary conception of time» en KronoScope 6, 2, 2006, p 205-229.

[8] Dreyfus, H. L.: Being-in-the-world: a commentary on Heidegger's Being and time, division I. Cambridge, Mass.: MIT Press, 1993, p. 170.

[9] Martínez Guzmán, V.: Podemos hacer las paces. Reflexiones éticas tras el 11-S y el 11-M. Bilbao: Desclée de Brower, 2005

[10] Comins Mingol, I. y Martínez Guzmán, V.: «Del miedo a la alteridad al reconocimiento del cuerpo: una perspectiva desde la filosofía para la paz» en Investigaciones Fenomenológicas monográfico 2 (Cuerpo y Alteridad), 2010, p 37-60

[11] Reardon, B.: Sexism and the War System. New York/London: Teachers College, Columbia University, 1985.

THÉMATA. Revista de Filosofía, №52 julio-diciembre (2015) pp.: 147-158 doi: 10.12795/themata.2015.i52.08 
Una forma de reaccionar a ese miedo es mediante la dominación de las otras y provoca el sexismo, dominar la tierra, someter las otras culturas y saberes, convirtiendo el conocimiento de los seres humanos blancos, adultos, masculinos de Occidente, en la sabiduría dominante y los otros saberes en sometidos. ${ }^{12} \mathrm{El}$ otro es entendido como alienus, alius, ${ }^{13}$ ajeno, extraño, extranjero y comenzamos la construcción social del «enemigo». El miedo que produce la alteridad genera violencia. Caemos en la tentación de la hybris, de la arrogancia de pensar que somos como imaginamos que son los dioses. Entonces, según la mitología griega, la justicia que viene es la venganza, Némesis.

Otra forma de reaccionar, desde nuestra propuesta de filosofía para hacer las paces, consiste en asumir con humildad nuestra fragilidad y el carácter relacional e intersubjetivo de las relaciones humanas, y promover políticas que encaren nuestro miedo y se basen en este carácter relacional. Es desde esta perspectiva que venimos afirmando que la violencia será la ruptura de esa intersubjetividad básica y originaria. Ahora el otro ya no es alius, ajeno, extraño, sino alter, los dos somos el uno para el otro (altera pars), estamos juntos, somos prójimos, y por eso podemos llegar a entendernos, a establecer un diálogo intercultural, a actuar con criterios de justicia e, incluso a amarnos. ${ }^{14}$ Siguiendo con la mitología griega, la justicia ahora ya no es venganza, Némesis, sinó Dikē, hermana del buen gobierno (Eunomia) y la paz (Eirēnē).

Por consiguiente, desde nuestra propuesta de filosofía para hacer las paces, la experiencia original del filosofar, consiste en quedarnos atónitos frente al descubrimiento de nuestra dependencia e interrelación con la tierra y los otros seres humanos. Desde esta experiencia de intersubjetividad y la asunción de nuestra fragilidad necesitamos nuevas formas de pensar la política, desligada de la violencia y atenta a la interculturalidad: a la interpelación de nuestra cultura desde las otras culturas y a interpelar las otras culturas desde la nuestra, pues todas nos constituimos en mutua reciprocidad. ${ }^{15}$

\section{Política desde la intersubjetividad desligada de la violencia}

A continuación, me referiré al famoso texto de Weber que vincula el Estado al uso legítimo de la violencia, para defender con Arendt que la política surge del estar juntos (Togetherness) y el poder (Macht) hay que desvincularlo de la violencia (Gewalt) aunque en alemán muchas veces van unidos: Por

[12] Foucault, M.: Genealogía del racismo. De la guerra de las razas al racismo de Estado. Madrid: La Piqueta/Endymion, 1992.

[13] Panikkar, R.: Pau i interculturalitat. Una reflexió filosòfica. Barcelona: Proa, 2004.

[14] Boltanski, L.: El amor y la justicia como competencias: tres ensayos de sociología de la acción. Buenos Aires: Amorrortu, 2000. Ricoeur, P.: Caminos del reconocimiento. Madrid: Trotta, 2005.

[15] París Albert, S. y Martínez Guzmán, V.: «Interculturalidad y conflicto. Una perspectiva desde la Filosofía para la Paz» en Investigaciones fenomenológicas 7, 2010, p 85-97.

THÉMATA. Revista de Filosofía, Nº52 julio-diciembre (2015) pp.: 147-158 doi: 10.12795/themata.2015.i52.08 
ejemplo, la «división de poderes» es en alemán la «división de violencias» (die Gewaltenteilung). En este contexto, una expresión política de la intersubjetividad será la propuesta de Arendt de considerar el poder como la capacidad de concertación de los seres humanos que nos dará una nueva concepción noviolenta de la política.

La forma de entender la política que vincula el Estado con la violencia podemos ilustrarla con el texto de Weber. "Estado es aquella comunidad humana que, dentro de un determinado territorio (el "territorio» es el elemento distintivo), reclama (con éxito) para sí el monopolio de la violencia física legítima». A las demás asociaciones e individuos se les concede el derecho a la violencia física en la medida en que el Estado lo permite, pues es la única fuente del «derecho» a la violencia. "Política significará, pues, para nosotros, la aspiración a participar en el poder entre los distintos Estados o, dentro de un mismo Estado, entre los distintos grupos de hombres que lo componen».

"Quien hace política aspira al poder; al poder como medio para la consecución de otros fines (idealistas o egoístas) o al poder "por el poder", para gozar del sentimiento de prestigio que él confiere». En definitiva «El Estado como todas las asociaciones políticas que históricamente lo han precedido, es una relación de dominación de hombres sobre hombres, que se sostiene por medio de la violencia legítima... Para subsistir necesita, por tanto, que los dominados acaten la autoridad que pretenden tener quienes en ese momento dominan». ${ }^{16}$ Ahí es donde surge el concepto de legitimación de la violencia cuando es usada por quienes tienen el poder del estado.

La alternativa en que venimos trabajando hace años ${ }^{17}$ se basa en la interpretación de la relación entre intersubjetividad y política propuesta por Hannah Arendt. ${ }^{18}$ La tercera de las actividades de la vita activa, según Arendt, es la acción que tiene como condición la pluralidad. El hecho de que los hombres, en plural, no el Hombre, vivan en la Tierra y habiten el mundo. Para Arendt todos los aspectos de la condición humana (parece que también la labor y el trabajo), se relacionan con la política. Pero la pluralidad no sólo es la conditio sine qua non, sino la conditio per quam, de toda vida política. Vivimos en pluralidad y nos organizamos políticamente. En esta pluralidad los seres humanos somos iguales para poder entendernos y somos diferentes, diferencia que posibilita el discurso y la acción. En mi interpretación, si no fuéramos iguales no podríamos entendernos, si no fuéramos diferentes no tendríamos nada que decir. Cada ser humano es un agente, "toma la iniciativa» y se revela en la acción y el discurso «cuando las personas están con otras... en pura contigüidad humana (where people are with others... in sheer human togetherness;

[16] Weber, M.: El político y el científico. Madrid: Alianza Editorial, 1988, p. 83-85.

[17] Martínez Guzmán, V.: Filosofía para hacer las paces. Barcelona: Icaria, p. 122 ss.

[18] Arendt, H.: La condición humana. Barcelona: Ediciones Paidós, 1996.

THÉMATA. Revista de Filosofía, №52 julio-diciembre (2015) pp.: 147-158 doi: 10.12795/themata.2015.i52.08 
wo Menschen miteinander... sprechen und agieren)». Esta contigüidad humana sería, a mi juicio, la interpretación de Arendt, de la intersubjetividad.

La ruptura de esta contigüidad convierte a los otros en enemigos y usa la violencia. Es una explicación de Arendt semejante a nuestra propuesta de que la violencia es la ruptura de la intersubjetividad. En la violencia que rompe la contigüidad humana, el discurso no revela a sus agentes y se convierte en "mera charla», medio para alcanzar un fin; la acción carece de significado.

La falta de predicción del resultado de las acciones es una muestra de la fragilidad humana. Desgraciadamente, cuando perdemos el control de nuestras acciones y llegamos a superar los fines por los medios que utilizamos, podemos desencadenar la violencia y, entonces, la guerra se convierte en el árbitro final de esa pérdida de control. Por eso, como dice Arendt, y nosotros mismos venimos proponiendo, la política, la vida en común en la forma de la polis, es otra forma de hacer frente a nuestra fragilidad para que no genere violencia ni miedo, al que ya nos hemos referido.

Por consiguiente, para esta autora, "La esfera política surge de actuar juntos, de "compartir palabras y actos". $\gg{ }^{19}$ En el discurso y en la acción, en la esfera pública, es donde nos aparecen las cosas y ejercemos el poder.

Contrariamente al texto que hemos visto de Weber, hay que desvincular el poder de la violencia:

«Poder corresponde a la capacidad humana, no simplemente para actuar, sino para actuar concertadamente. El poder nunca es propiedad de un individuo; pertenece a un grupo y sigue existiendo mientras que el grupo se mantenga unido». ${ }^{20}$ Considera a la palabra "poder» equivalente a dynamis y a potentia y del término en alemán Macht destaca su procedencia de mögen y möglich y no de machen, para resaltar su carácter potencial; es independiente de los factores materiales como el número, o los medios. De la capacidad de concertar viene el poder de los países pequeños y poderosos que pueden aventajar a los ricos o el poder de la noviolencia.

Por otra parte es interesante esta relación entre el poder y el grupo. El poder existe mientras permanece el grupo unido, que es quien da legitimidad al poder. Por consiguiente, habrá que revisar expresiones como la «soledad del poder» frente a la «desafección» de la gente hacia la política, porque más que una «carga de responsabilidad» como a veces se hace creer, lo que puede estar pasando es que se está perdiendo legitimidad, al separarse del grupo.

En cambio la violencia es una acción que se distingue por el uso de herramientas de ahí la influencia de la revolución tecnológica en la actitud bélica. La «verdadera sustancia» de la acción violenta se rige por la categoría medios-fin.

[19] Ibid. p. 224

[20] Arendt, H.: «Sobre la violencia» en Arendt, H.: Crisis de la república. Madrid: Taurus, 1998, p. 146.

THÉMATA. Revista de Filosofía, Nº52 julio-diciembre (2015) pp.: 147-158

doi: 10.12795/themata.2015.i52.08 
La principal característica de esta categoría aplicada a los asuntos humanos «ha sido siempre la de que el fin está siempre en peligro de verse superado por los medios a los que justifica y que son necesarios para alcanzarlo». ${ }^{21}$

Encontramos, pues, en Arendt, los elementos que proponíamos en la relación entre la experiencia de admiración o asombro y la intersubjetividad: asunción de la fragilidad humana como síntoma de la interdependencia entre los seres humanos, importancia del habla o el discurso donde nos revelamos como seres humanos, y surgimiento de la política desde esta interrelación humana que nos ayuda a afrontar nuestra fragilidad y el descubrimiento de la alteridad, desde nuestra capacidad de concertación, para evitar la violencia donde los medios sobrepasan a los fines. La violencia se iniciaría con la ruptura de esa intersubjetividad.

Sin embargo, no queremos caer en una visión ingenua de la política. Sobre todo, porque más que la estética académica, nos preocupa el sufrimiento que unos seres humanos podemos producir a otros, haciendo que «lleven su vida por debajo de sus capacidades como seres humanos», apelando a la etimología de sufrimiento (sub, fero/ferre). Por esta razón estudiamos ${ }^{22}$ también autores $\mathrm{y}$, en este caso autoras, ${ }^{23}$ que resaltan más el carácter conflictivo y agonal, en el sentido de juegos con combates y lucha competitiva, de la política. Mouffe considera que las propuestas de inspiración liberal democrática, en la que incluyen también la tercera vía de la social democracia, no consiguen captar el papel fundamental de lo político que se basa constitutivamente en el antagonismo y en la exclusión originaria. Para Mouffe «lo político» está ligado a la dimensión de antagonismo y de hostilidad que existen en las relaciones humanas. El antagonismo se manifiesta como diversidad en las relaciones sociales. Por su parte «la política», apunta a establecer un orden, a organizar la coexistencia humana en condiciones que son siempre conflictivas, pues están atravesadas por «lo» político. De hecho, en nuestra propuesta de filosofía para hacer las paces, siguiendo la tradición de la Investigación para la Paz, ${ }^{24}$ venimos trabajando la transformación de los conflictos por medios pacíficos, en donde la capacidad humana de concertación, en el sentido que hemos visto de Arendt es fundamental, pero en un contexto realista de relaciones humanas donde los conflictos están presentes. ${ }^{25}$

[21] Ibid. p. 112.

[22] Martínez Guzmán, V.: «Paz y política en el mundo contemporáneo» en Martínez López, F. y Muñoz, F. A.: Políticas de Paz en el Mediterráneo. Madrid: Biblioteca Nueva, 2007, p. 111-122.

[23] Mouffe, C.: El retorno de lo político: comunidad, ciudadanía, pluralismo, democracia radical. Barcelona: Paidós, 1999. La paradoja democrática. Barcelona: Gedisa, 2003.

[24] Lederach, J. P.: Construyendo la paz. Reconciliación sostenible en sociedades divididas. Bilbao: Gernika Gogoratuz, 1998. La imaginación moral. El arte y el alma de la construcción de la paz. Bilbao/Gernika-Lumo: Bakeaz/Gernika Gogoratuz, 2007. Preparing for Peace: Conflict Transformation Across Cultures. Syracuse (NY): Syracuse University Press, 1995.

[25] París Albert, S.: Filosofía de los conflictos. Barcelona: Icaria, 2009.

THÉMATA. Revista de Filosofía, №52 julio-diciembre (2015) pp.: 147-158 doi: 10.12795/themata.2015.i52.08 
Además, para seguir quitándole ingenuidad a nuestro planteamiento, estamos estudiando el problema de la corrupción en relación con la llamada crisis económica. Parece que ahora es «crisis» porque ha afectado a las clases medias de los países ricos, mientras que nosotros ya veníamos denunciándola cuando se suponía que todo iba bien, pero se incrementaban las desigualdades entre los seres humanos. Así, inspirados por Kant ya advertíamos ${ }^{26}$ el peligro de los políticos que adaptan la moral a su conveniencia, aplicando sólo la primera parte de la máxima evangélica de ser prudentes o sagaces (klug en Kant, phronimos en el griego del evangelio de Mt 10, 16) como las serpientes. Se olvidaban así, de la segunda parte que pone freno a esa sagacidad apelando a la candidez o actuación "sin falsedad» de las palomas (ohne Falsch en Kant, akéraios en el mismo evangelio) y, por consiguiente, estableciendo una relación entre moral y política.

Actualmente se llega a hablar ${ }^{27}$ de cleptopía y cleptocracia: del gobierno de los ladrones y corruptos. Es desde la política como capacidad de concertación y la legitimación del poder porque su ejercicio siempre procede del grupo, como hemos visto en Arendt, desde donde podemos interpelar y denunciar esa corrupción y reclamar la moralización de la política.

También en tiempos en los que la crisis era sólo para los grupos y países empobrecidos, veníamos defendiendo una cultura de la austeridad que provocaba una sonrisa burlona desde la pretendida abundancia. Es una noción que, por una parte, está en la base de los estudios críticos con la relación de los estudios de la paz y el desarrollo ${ }^{28}$ o estudios de postdesarrollo ${ }^{29}$ y por otra inspira también las propuestas más recientes sobre el decrecimiento. ${ }^{30}$ Illich hablaba de la noción de «austero» en el sentido de «sobrio» reducido a lo necesario y apartado de lo superfluo o agradable; una severidad ligada a rectitud, pero evitando los matices negativos que estos términos tienen en la actualidad, porque son virtudes que se ejercen con alegría: eutrapelia decía citando a Aristóteles y Tomás de Aquino. Era una defensa de la austeridad, precisamente, para transformar las desigualdades, la marginación y la exclusión. Sin embargo, ahora se impone una austeridad que genera más desigualdades, marginación y exclu-

[26] Martínez Guzmán, V.: «L’Educació per a la pau, la tolerància i la convivència (Una perspectiva des de la filosofia del discurs i la comunicació)» en Gabinete Psicopedagógico De Torrent: VII Jornadas Municipales de Psicopedagogía. Las Transversales. Torrent (València), 1996, p. 121-138.

[27] Taibbi, M.: Cleptopia: fabricantes de burbujas y vampiros financieros en la era de la estafa. Madrid: Lengua de Trapo, 2012.

[28] Illich, I.: La convivencialidad. Barcelona: Barral Editores, 1974. «Desvincular paz y desarrollo» en Alternativas II. México: Joaquín Moritz/Planeta, 1988, p. 165-178.

[29] Sachs, W., ed. Diccionario del Desarrollo. Una guía del conocimiento como poder. Lima: Pratec: Proyecto Andino de Tecnologías Campesinas.

[30] Latouche, S.: La sociedad de la abundancia frugal. Contrasentidos y controversias del decrecimiento. Barcelona: Icaria, 2012.

THÉMATA. Revista de Filosofía, N ${ }^{\circ} 52$ julio-diciembre (2015) pp.: 147-158

doi: 10.12795/themata.2015.i52.08 
sión. Por eso Latouche ha dejado de usar austeridad y habla de una «sociedad de abundancia frugal».

Por consiguiente, el marco conceptual que venimos proponiendo que interrelaciona intersubjetividad, con política e, incluso, aunque aquí me he referido menos a ello, con interculturalidad, ${ }^{31}$ no es ingenuo sino que tiene en cuenta otras visiones en donde se hace explícita la importancia de los conflictos y, sobre todo, se está atento al sufrimiento que podemos producir y que genera desigualdades, marginación y exclusión. En este sentido seguimos atentos a cualesquiera formas de marginación de colectivos desempoderados, a los que no se les permite el ejercicio del poder como capacidad de concertación y, por consiguiente, se les priva de la política, lo cual es injusto. A un ejemplo de esta «injusticia» me refiero para finalizar.

\section{Performatividad, silenciamiento ilocucionario e injusticia discursiva}

Otro ejemplo de intersubjetividad será la noción de performatividad que expresa, desde la fenomenología lingüística, la interrelación entre los seres humanos que tienen "como tarea común» el habla. Para que un acto de habla sea afortunado el hablante tiene unas intenciones y sigue unas convenciones que constituyen la fuerza ilocucionaria o performativa de lo que se dice, pero que intersubjetivamente, ha de ser captada o aprehendida (uptake) por el oyente. Aquí aplicaré una noción de filosofía feminista en uno de los últimos números de la revista Hypatia: la «injusticia discursiva»: Cuando en las relaciones intersubjetivas o interculturales, en razón del género o, en general, del hecho de que los emisores de los actos de habla sean personas o miembros de grupos desempoderados, no producen en los oyentes el efecto performativo de aprehensión que el emisor pretende, porque se les desprecia o se le considera de menor "categoría", lo cual aumenta su desempoderamiento. Sería un ejemplo de la violencia como ruptura de la intersubjetividad, explicado técnicamente con la terminología de los actos de habla porque se priva a determinados emisores de que digan lo que pretenden decir.

Se han llegado a usar dos expresiones "silenciamiento ilocucionario»" ${ }^{32}$ e «injusticia discursiva». ${ }^{33}$ Es un ejemplo de cómo una terminología aparentemente tan técnica como la de los actos de habla, nos puede ayudar a comprender la intersubjetividad de las relaciones humanas, expresada en este caso

[31] París Albert, S. y Martínez Guzmán, V.: «Interculturalidad y conflicto. Una perspectiva desde la Filosofía para la Paz» en Investigaciones fenomenológicas 7, 2010, p 85-97.

[32] Langton, R.: «Speech Acts and Unspeakable Acts» en Philosophy \& Public Affairs 22, 4, 1993, p 293-330.

[33] Kukla, R.: «Performative Force, Convention, and Discursive Injustice» en Hypatia 29, 2, 2014, p 440-457.

THÉMATA. Revista de Filosofía, №52 julio-diciembre (2015) pp.: 147-158 doi: 10.12795/themata.2015.i52.08 
en el habla, y sus posibles rupturas, en nuestra interpretación origen de las violencias.

Sabemos ${ }^{34}$ que la fuerza performativa y la estructura pragmática de un acto de habla dependen de un elaborado conjunto de convenciones discursivas que fijan e interpretan la fuerza de un acto de habla, junto con las circunstancias materiales del acto. Desde este contexto, Kukla quiere explorar un tipo de «incapacidad discursiva» (discursive incapacity). Argumenta que, a veces, a un/a hablante de un grupo social desfavorecido le resulta difícil o imposible aplicar las convenciones de forma normal, con el resultado de que la fuerza performativa de sus emisiones queda distorsionada de tal manera que aumenta su desventaja. Aunque su perspectiva es la de género y se refiere a las mujeres, el mismo análisis se puede aplicar a problemas de raza, clase, región o discapacidad, por ejemplo. A esta situación la llama de «injusticia discursiva» de forma paralela a la llama «injusticia epistémica». ${ }^{35}$

Como hemos mencionado en la introducción de este apartado, según Austín para que un acto de habla sea afortunado, se ha de producir, entre otras características, el efecto ilocucionario de aprehensión (uptake). Es decir quien oye tiene que captar la fuerza con la que quien emite ha hecho su emisión. Quien habla puede tener la intención y seguir las convenciones adecuadas para hacer una promesa, por ejemplo, pero el acto de habla sólo será «afortunado» si quien oye capta o aprehende esa fuerza de la emisión, y la toma como una promesa, y no, por ejemplo, como una advertencia. De hecho, esta interrelación por la que hablantes y oyentes quedamos ligados ( $m y$ word is my bond), unos seres humanos a otros es una expresión de la intersubjetividad que venimos estudiando, desde la fenomenología lingüística de lo que hacemos al hablar. Así mismo está en la base, por ejemplo, de la Ética comunicativa o del discurso de Apel y Habermas. ${ }^{36}$

Pues bien, Kukla considera que la fuerza performativa de un acto de habla no se limita a este efecto de aprehensión pragmática en el momento de la emisión, ni a la clarificación de las intenciones y las convenciones pragmáticas. Pone el ejemplo de un matrimonio religioso que se celebra sin implicaciones legales. Un transeúnte que lo observa sin entender estos ritos, puede tener una aprehensión equivocada de lo que se está realizando y pensar en otro tipo de ceremonia. Esta mala aprehensión de la fuerza ilocucionaria del acto de habla del matrimonio puede agravarse, si el comportamiento posterior de la pareja o de los invitados, no son acciones coherentes con el matrimonio. Por consiguien-

[34] Austin, J. L.: Palabras y Acciones. Cómo hacer cosas con palabras. Buenos Aires: Paidós, 1971. How to do things with words. Oxford/London/New York: Oxford University Press, 1976.

[35] Fricker, M.: Epistemic injustice: power and the ethics of knowing. Oxford: Oxford University Press, 2009.

[36] Habermas, J.: «¿Qué significa pragmática universal?» en Habermas, J.: Teoría de la Acción Comunicativa: Complementos y Estudios previos. Madrid: Cátedra, 1989, p. 299-368.

THÉMATA. Revista de Filosofía, №52 julio-diciembre (2015) pp.: 147-158

doi: 10.12795/themata.2015.i52.08 
te, se requiere el seguimiento posterior a la emisión del acto de habla, de las convenciones adecuadas que hagan aprehender la fuerza del acto de habla emitido. Al cumplimiento de esta serie de convenciones posteriores a la emisión del acto de habla y que son también fundamentales para la aprehensión de la fuerza ilocucionaria, Kukla le llama «aprehensión social» (social uptake). El punto crucial es que las convenciones no terminan artificialmente en el momento de la emisión. Se extienden temporalmente e incluyen realizaciones (perfomances) sociales después, además de antes y durante la emisión. Es el detalle de todas estas convenciones pragmáticas pero también sociales las que configuran el tipo de acto de habla que estamos realizando.

Por consiguiente hay un enorme número de convenciones que se han de cumplir para que un hablante esté autorizado a emitir un acto de habla A en un contexto C. Si usa las palabras correctas, el tono y los gestos adecuados, para emitir un acto de habla $\mathrm{A}$ en un contexto $\mathrm{C}$, de acuerdo con las correspondientes convenciones, le será dada la aprehensión de ese acto A. Sin embargo, algunas veces, por ser mujer o miembro de algún grupo de identidad social desempoderada, el proceso queda alterado. Un hablante puede cumplir las convenciones que la autora llama de entrada (input) para la realización del acto de habla $\mathrm{A}$, pero por razones de género, recibe una aprehensión de un acto $\mathrm{B}$, porque las convenciones de salida (output) son diferentes por el hecho de ser mujer. De esta manera la fuerza de sus palabras, queda fuera de su control, y la convierten en víctima de una injusticia discursiva. Se le priva de actuar autónomamente como agente de discurso. Se produce un tipo de infortunio (infelicity), siguiendo una vez más a Austin, que frustra el camino entre la realización (performance) y la aprehensión (uptake). Además el acto de habla B que acaba realizando, a pesar de tener las intenciones y seguir las convenciones para realizar el acto A, amplían su situación de persona desfavorecida y desapoderada atribuidas a su identidad de género. "Las víctimas de la injusticia discursiva, en virtud de sus identidades sociales desfavorecidas, son menos capaces de negociar de manera hábil y de utilizar las convenciones discursivas como herramientas de comunicación y acción que otros». ${ }^{37}$

Pone el ejemplo de una mujer jefa de un $95 \%$ de hombres en una planta de una industria de maquinaria pesada. La jefa emite un orden con la intención de que sea una orden y siguiendo las convenciones pragmáticas para que sea entendida como una orden. Sin embargo, por el hecho de ser mujer, la fuerza de su acto de habla es aprehendida como un ruego, porque por las convenciones sociales más allá de las pragmáticas, a una mujer (o a cualquier ser humano perteneciente a un colectivo desempoderado) se le priva de tener el control de la fuerza performativa de lo que quiere decir, de lo que quiere hacer con sus palabras. Es más, el hecho de que con controle la fuerza con la que quiere decir lo

[37] Kukla, op. cit. p. 445

THÉMATA. Revista de Filosofía, Nº52 julio-diciembre (2015) pp.: 147-158 doi: 10.12795/themata.2015.i52.08 
que dice, ahonda aún más en su situación de desventaja o desapoderamiento. Se produce así una injusticia discursiva. En mi interpretación se rompe la intersubjetividad originaria que nos constituye a hombres y mujeres como seres humanos en reciprocidad, iniciando un tipo de violencia.

Por otra parte, utiliza también la noción de «silenciamiento ilocucionario». El silenciamiento ilocucionario, estudiado también desde la perspectiva de las mujeres, se da en el marco de las formas en que los poderosos pueden dejar sin hablar, sin voz o discurso, a quienes no tienen poder. Ciertamente se puede hacer mediante la amenaza, la condena o el confinamiento a la soledad. Sin embargo hay todavía una forma más sutil y menos dramática, que consiste en dejar hablar, permitir emitir las palabras, pero que éstas no realicen las acciones de la fuerza ilocucionaria del acto de habla, de nuevo en el sentido de Austin, de cómo hacemos cosas con palabras. Según Kukla explica la tesis de Langton, una persona es silenciada locucionariamente si no se le permite hablar, perlocucionariamente si no se causan los efectos del acto de habla emitido, e ilocucionariamente, si es incapaz de realizar los actos de habla que intenta al hablar, porque el acto de habla no puede recibir el correcto efecto ilocucionario de aprehensión o captación (uptake) de la fuerza con que dice lo que dice, de nuevo siguiendo a Austin. El silenciamiento ilocucionario sería un caso límite de lo que le interesa a Kukla porque al no darse el efecto ilocucionario de aprehensión, no habría acto de habla. En cambio, como hemos visto, a esta autora le interesa cuando se produce un acto de habla diferente debido a que el efecto ilocucionario de aprehensión es diferente de lo que sería en las convenciones normales porque quien realiza la emisión es miembro de una comunidad desfavorecida.

Ciertamente puede haber casos en donde también alguien "poderoso» no consiga que se logre la aprehensión afortunada de las intenciones y las convenciones de su acto de habla. Por ejemplo, un jefe enamorado sinceramente de su secretaria, no controla tampoco la fuerza performativa de su emisión. Precisamente, por su «elevado» estatus teme que su declaración de amor sea aprehendida como una orden que requiere obligación. Según Kukla es un ejemplo más de que hablar es un proyecto colaborativo. En mi interpretación, es una muestra de intersubjetividad de las relaciones humanas que aquí hemos venido defendiendo para reconceptualizar la política y facilitar la interculturalidad. 